\title{
Application of GC/EIMS in Combination with Semi-Empirical Calculations for Identification and Investigation of Some Volatile Components in Basil Essential Oil
}

\author{
Mamoun S. M. Abd El-Kareem ${ }^{1 *}$, Mohamed Abd El Fattah Rabbih', \\ Ezzat Taha Mohamed Selim¹, Elsherbiny Abd El-monem Elsherbiny², \\ Ayman Yahya El-Khateeb ${ }^{3}$ \\ ${ }^{1}$ Molcular and Atomic Physics Unit, Experimental Nuclear Physics Dept., Nuclear Research Centre, Egyptian \\ Atomic Energy Authority, Inshas, Cairo, Egypt \\ ${ }^{2}$ Plant Pathology Department, Faculty of Agriculture, Mansoura University, Mansoura, Egypt \\ ${ }^{3}$ Agricultural Chemistry Department, Faculty of Agriculture, Mansoura University, Mansoura, Egypt \\ Email: *mamoun_sarhan@yahoo.com
}

Received 23 December 2015; accepted 27 March 2016; published 30 March 2016

Academic Editor: Ilia Brondz, Norwegian Drug Control and Drug Discovery Institute, Norway

Copyright (C) 2016 by authors and Scientific Research Publishing Inc.

This work is licensed under the Creative Commons Attribution International License (CC BY). http://creativecommons.org/licenses/by/4.0/

c) (i) Open Access

\begin{abstract}
Volatile components in the extracts of basil leaves (Ocimum basilicum L.) were identified by gas chromatography/mass spectrometry (GC/MS) with electron ionization (EI) mode. The major volatile components of basil under investigation are $\alpha$-pinene, sabinene, $\beta$-pinene, d-limonene, eucalyptol, l-linalool and estragole. Electron ionization mass spectra of these compounds have been obtained and investigated. Furthermore, the semi-empirical MNDO [Modified Neglect of Diatomic Overlap] method was used to calculate the thermochemical data for the structural properties of these compounds.
\end{abstract}

\section{Keywords}

Gas Chromatograph, Mass Spectrometer, Semi-Empirical Calculations, Basil Essential Oil

\footnotetext{
${ }^{*}$ Corresponding author.

How to cite this paper: El-Kareem, M.S.M.A., Rabbih, M.A.E.F., Selim, E.T.M., Elsherbiny, E.A.E. and El-Khateeb, A.Y. (2016) Application of GC/EIMS in Combination with Semi-Empirical Calculations for Identification and Investigation of Some Volatile Components in Basil Essential Oil. International Journal of Analytical Mass Spectrometry and Chromatography, 4, 14-25. http://dx.doi.org/10.4236/ijamsc.2016.41002
} 


\section{Introduction}

The genus Ocimum is the largest genera in the lamiaceae family with more than 150 species [1]. Among these species of basil, $O$. basilicum is considered as the major essential oil crop and cultivated commercially in different regions all over the world [2]. All parts of basil plants were used in folk medicine for treatment of cold, sedative, coughs, removing heat and eliminating toxins as well as used in making flavoring and perfume [3].

Among the many studies to determine the volatile compounds in basil, the most have focused mainly on the detection and reported the chemical composition of the volatile components in the essential oil [4]-[9]. For this reason the employment of mass spectrometer has been proposed [10].

Mass spectrometer (MS) is one of the fastest-growing areas in analytical instrumentation. The use of mass spectrometry in support of synthetic, organic, and pharmaceutical chemistry is well established. Also, it is used in environmental research, forensic chemistry, essential oil and natural product analysis [10]. MS has the capacity to generate more structural information of an analyte than that can be determined by any other analytical technique [11]. The production of positive ions by electron ionization is a widely employed technique, as it can be utilized for the analysis of nearly all gases and volatile compounds [12].

On the other hand, quantum chemical (QCH) methods for the calculations of thermochemical data have been developed beyond the level of just reproducing experimental data. Also, they can now make accurate predictions where the experimental data are unknown or uncertain [13]. The semi-empirical molecular orbital methods of quantum chemistry [14]-[25] were widely used in computational studies of small and large molecules, particularly in organic chemistry and biochemistry. Thermochemical data for chemical compounds are essential for demands of the ever increasing development of science and technology. Such data as the different physicochemical parameters are important on the understanding of the chemical problems, like energetics of the chemical bonds, structural properties and reactivity or even in more applied field like chemical industry, medical and life science, military matters, etc. [26]. Elsherbiny A. Elsherbiny et al. [27] they have determined the chemical compositions of all components in the total ion chromatogram of Ocimum basilicum $\mathrm{L}$ and its concentrations.

The aim of the present work was to study some volatile compounds in Basil (Ocimum basilicum L) namely: $\alpha$-pinene, pabinene, $\beta$-pinene, dl-limonene, eucalyptol, L-linalool and estragole according to their mass spectra in combination with semi-empirical MNDO method to report some of their thermochemical data such as heats of formation, total and binding energies, ionization energy and dipole moment.

\section{Experimental}

\subsection{Plant Material}

The leaves of $O$. basilicum L. were collected in Mansoura, Egypt (latitude $31^{\circ} 3^{\prime} 0^{\prime \prime} \mathrm{N}$, longitude $31^{\circ} 23^{\prime} 0$ "E, temperature $24^{\circ} \mathrm{C}-30^{\circ} \mathrm{C}$, loam soil) from plants growing in the Mansoura University campus in July 2013. The taxonomic identification of plants was confirmed at the Botany Department, Faculty of Agriculture, Mansoura University, where a voucher specimen has been deposited.

\subsection{Extraction of the Essential Oil}

The air-dried leaves $(1.5 \mathrm{~kg}$ ) of $O$. basilicum L. were subjected to hydrodistillation using a Clevenger-type apparatus for 4 hours. The oily layer obtained on top of the aqueous distillate was separated and dried with anhydrous sodium sulfate $\left(\mathrm{Na}_{2} \mathrm{SO}_{4}\right)$. The extracted essential oil was kept in sealed air-tight glass vials and covered with aluminum foil at $4^{\circ} \mathrm{C}$ until used for GC/MS analysis and biological activity tests. The yield of the essential oil was $24.25 \%(\mathrm{v} / \mathrm{w})$.

\subsection{Gas Chromatography-Mass-Spectrometry}

GC/MS data were acquired using (Trace GC-ISQ mass spectrometer, Thermoscintific, USA) equipped with A3000 autosampler and TG-5MS Capillary column of $30 \mathrm{~m}$ length, $0.25 \mathrm{~mm}$ i.d. and $0.25 \mu \mathrm{m}$ film thickness. Temperature was programmed from $50^{\circ} \mathrm{C}-280^{\circ} \mathrm{C}$ at a rate of $10^{\circ} \mathrm{C} / \mathrm{min}$. Mass spectrometer in EI mode at $70 \mathrm{eV}$, source temperature, $200^{\circ} \mathrm{C}$; interface temperature, $220^{\circ} \mathrm{C}$; injector temperature, $220^{\circ} \mathrm{C}$. Diluted sample of $1 \mu \mathrm{l}$ injected in splitless mode and mass scan, 50 - 600 amu. Helium was used as a carrier gas with $1 \mathrm{~mL} / \mathrm{min}$ flow rate. The components of essential oil were identified tentatively by comparing their relative retention times and mass spectra with those of WILEY (Wiley Registry of Mass Spectral Data, 9th Edition Version 1.02) and NIST 
05 (NIST/EPA/NIH mass spectral library version 2.0d) mass spectral database.

\section{Theoretical Calculations}

The semi-empirical MNDO procedure [28] with the associated HyperChem professional 7.5 program [29] [30] was used for the structural investigation of the studied compounds in their ground and charged states-in the gas phase.

\section{Results and Discussion}

The total ion chromatogram of the Basil essential oil are shown in Figure 1 while the chemical composition of the essential oil of Ocimum basilicum is listed in Table 1 where the components are listed according to their elution on the TG-5MS column. Figures 2-8: shows the mass spectra of the studied compounds at $70 \mathrm{eV}$ while the main fragment ions and their relative intensities are listed in Table 2. The identification of the chemical constituents was assigned on the basis of comparison of their retention indices [6] and mass spectra in the database of the system.

The chemistry and reactivity of medicinal plants such as Basil (Ocimum basilicum L) have always been of great interest because of its importance role in the treatments of various kinds of diseases. Knowledge of mass spectrometric fragmentation mechanisms of the volatile components in Basil together with the calculated data

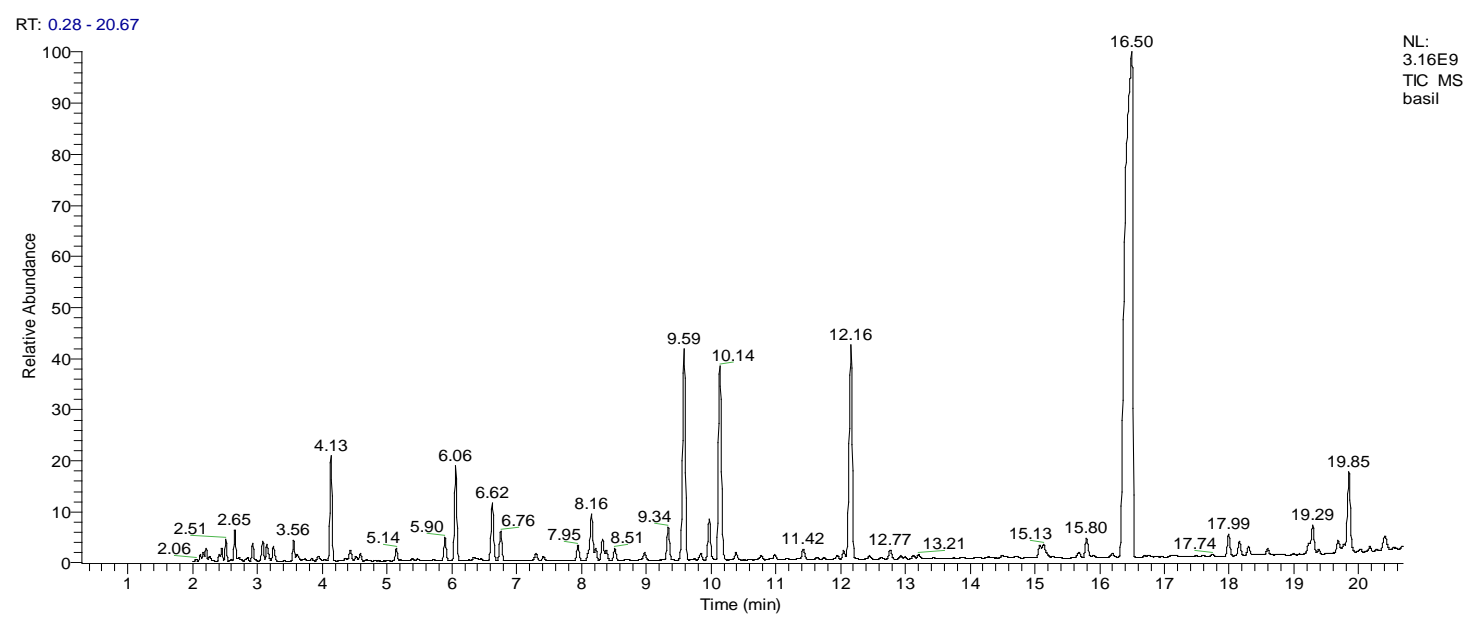

Figure 1. The total ion chromatogram of the Basil oil.

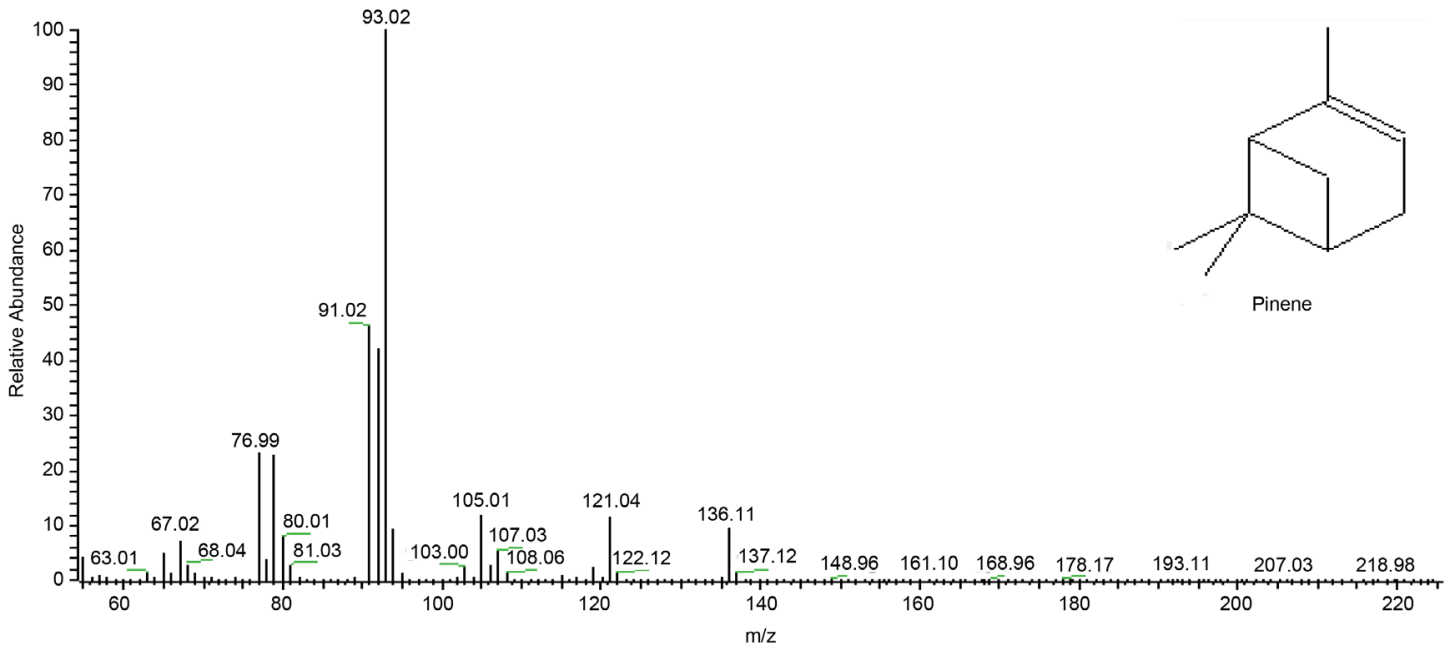

Figure 2. The mass spectrum of $\alpha$-pinene. 


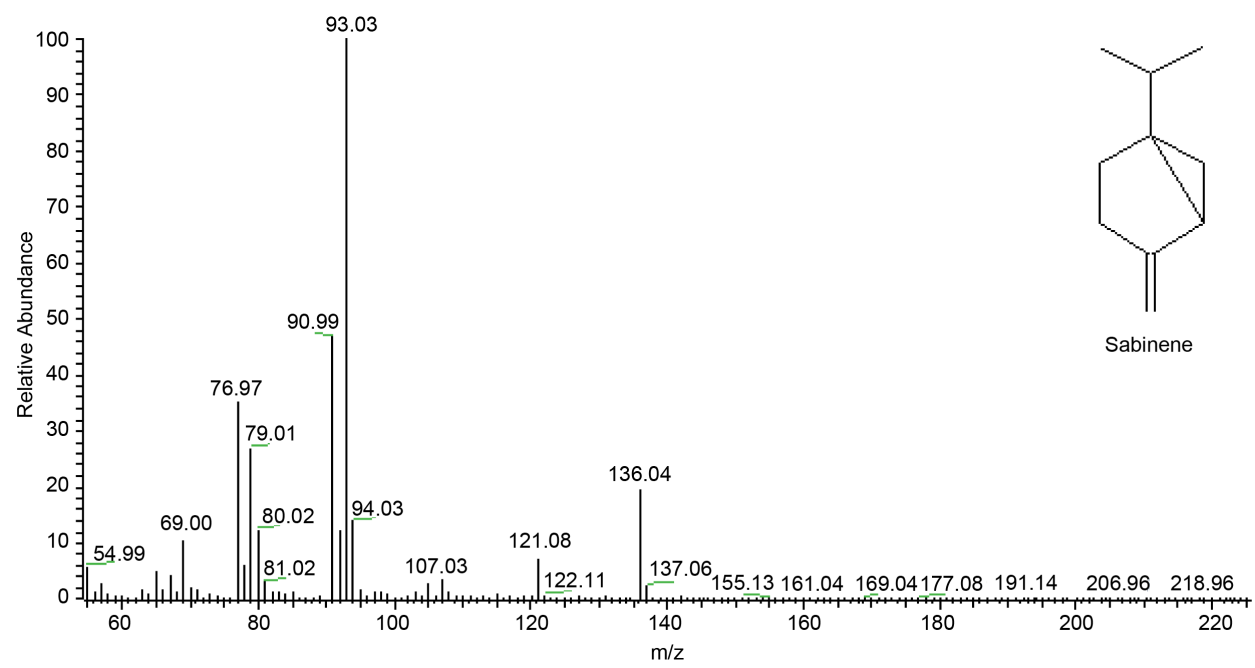

Figure 3. The mass spectrum of sabinene.

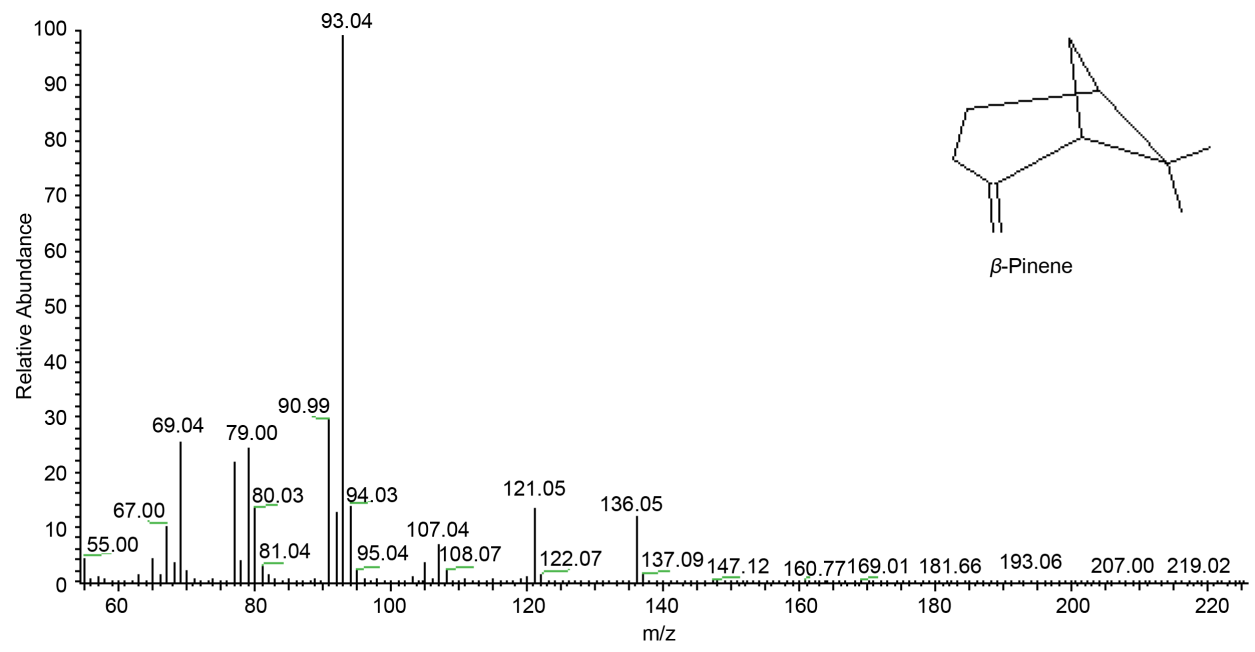

Figure 4. The mass spectrum of $\beta$-pinene.

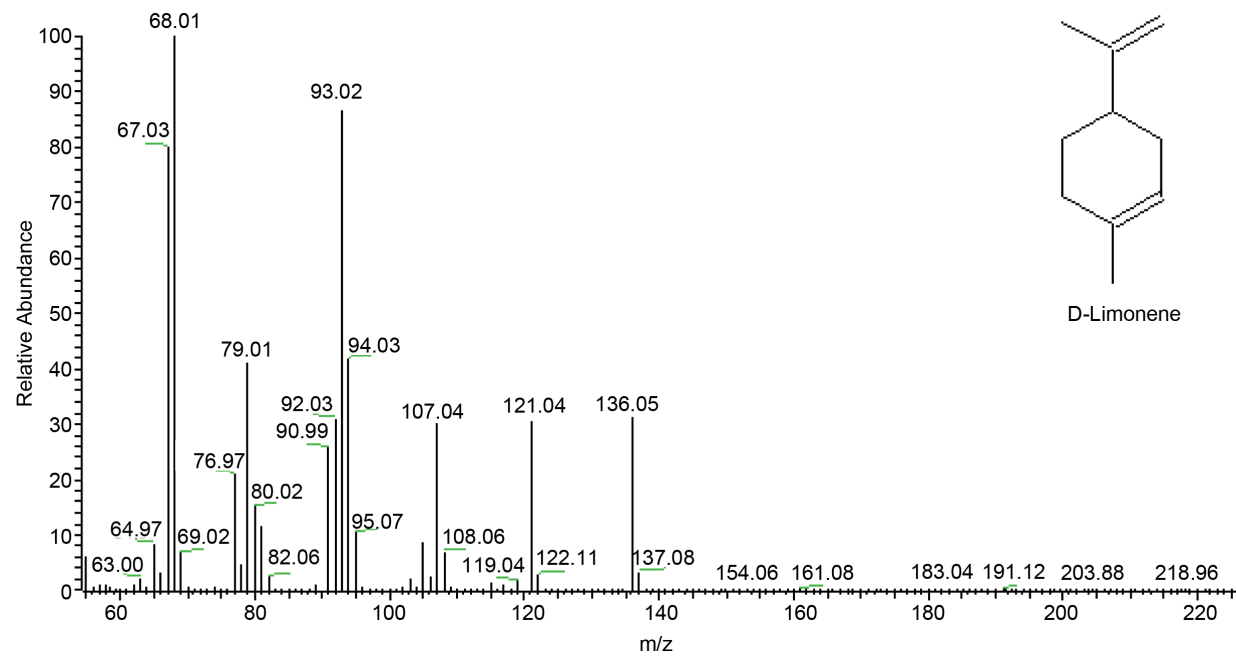

Figure 5. The mass spectrum of d-limonene. 


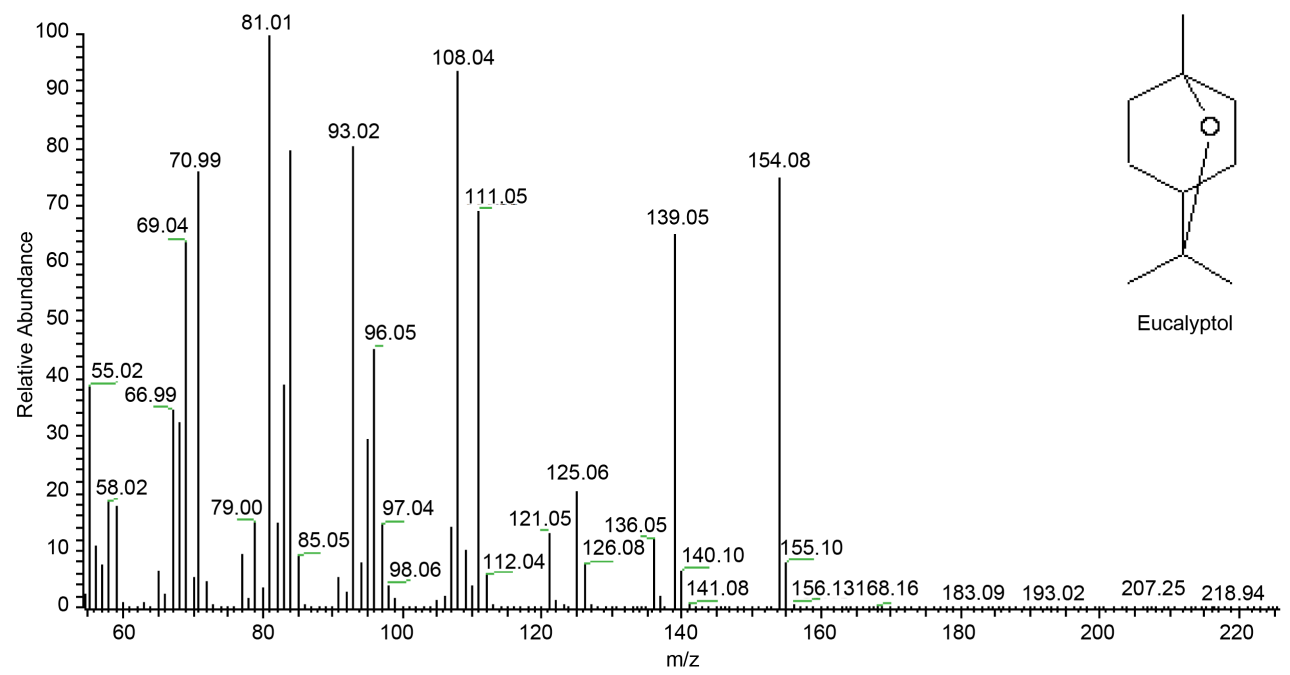

Figure 6. Mass spectrum of eucalyptol.

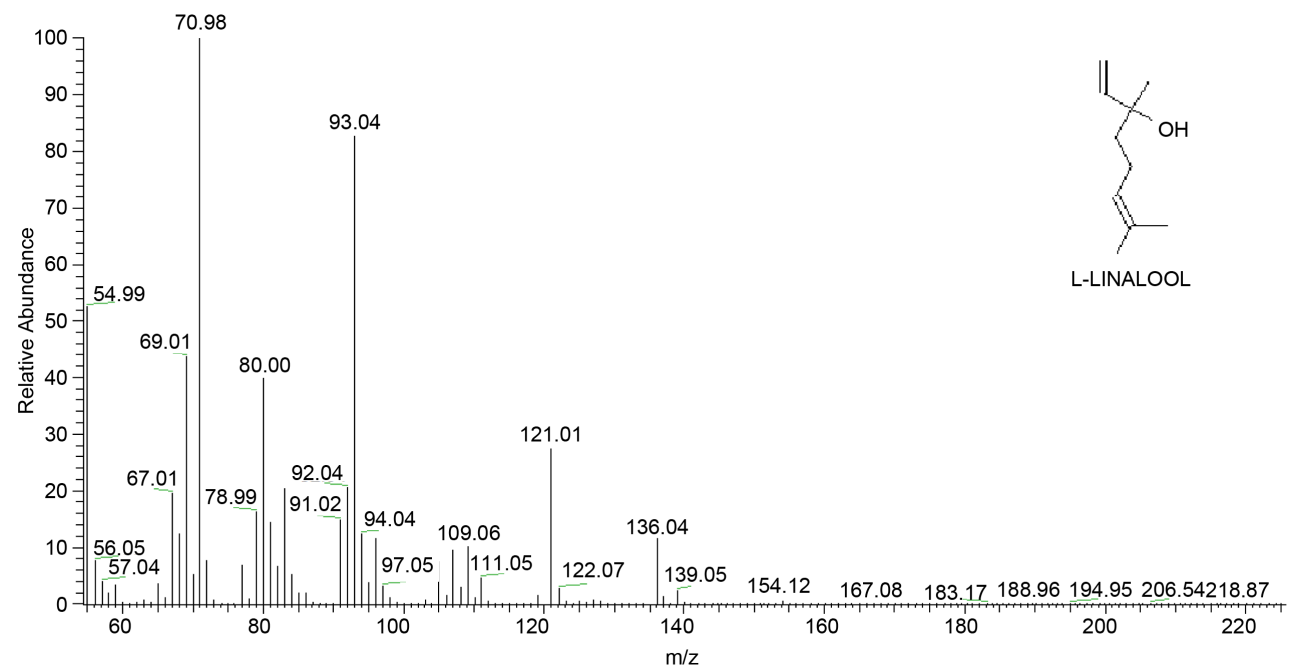

Figure 7. Mass spectrum of l-linalool.

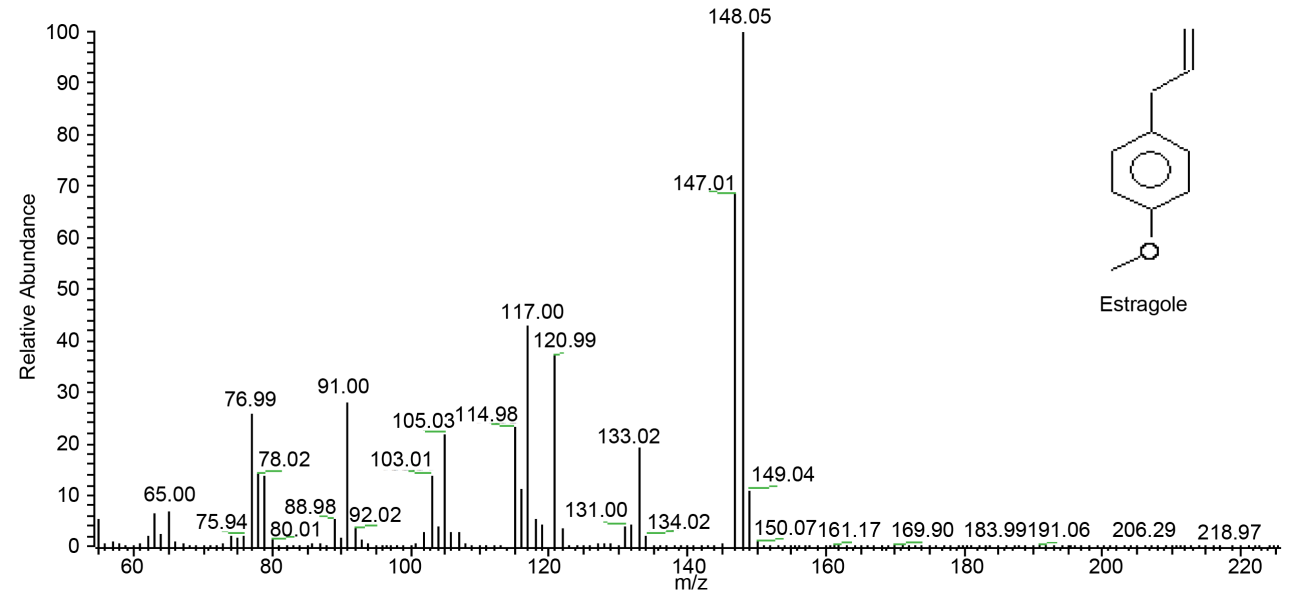

Figure 8. Mass spectrum of estragole. 
Table 1. Chemical composition of the main components of basil essential oil.

\begin{tabular}{ccccc}
\hline No. & Rt (min.) & Compound & Peak area (\%) & Molecular formula \& Molecular weight \\
\hline 1 & 6.62 & $\alpha$-pinene & 0.83 & $\mathrm{C}_{10} \mathrm{H}_{16}(\mathrm{MW}: 136)$ \\
2 & 7.95 & Sabinene & 0.22 & $\mathrm{C}_{10} \mathrm{H}_{16}$ (MW:136) \\
3 & 8.16 & $\beta$-pinene & 0.90 & $\mathrm{C}_{10} \mathrm{H}_{16}$ (MW:136) \\
4 & 9.59 & d-limonene & 3.2 & $\mathrm{C}_{10} \mathrm{H}_{16}$ (MW:136) \\
5 & 10.14 & eucalyptol & 3.19 & $\mathrm{C}_{10} \mathrm{H}_{18} \mathrm{O}$ (MW:154) \\
6 & 12.16 & l-linalool & 3.57 & $\mathrm{C}_{10} \mathrm{H}_{18} \mathrm{O}$ (MW:154) \\
7 & 16.50 & estragole & 19.67 & $\mathrm{C}_{10} \mathrm{H}_{12} \mathrm{O}$ (MW:148) \\
\hline
\end{tabular}

Table 2. Fragment ions and their relative intensities R I (\%) produced from of the studied compounds.

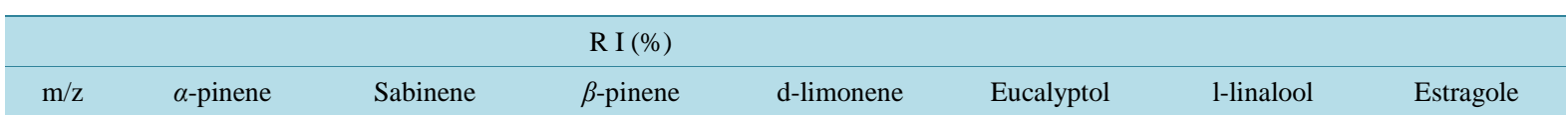

\begin{tabular}{|c|c|c|c|c|c|c|c|}
\hline 65 & - & 6 & 4 & 8 & - & - & 7 \\
\hline 67 & - & 5 & 10 & 80 & 33 & 22 & - \\
\hline 68 & - & - & 2 & 100 & 30 & 12 & - \\
\hline 69 & - & 11 & 27 & 6 & 62 & 44 & - \\
\hline 71 & - & - & - & - & 74 & 100 & - \\
\hline 77 & 23 & 37 & 22 & 21 & - & - & 24 \\
\hline 78 & 4 & 6 & 4 & - & - & - & 14 \\
\hline 79 & 23 & 26 & 24 & 41 & 14 & 17 & 13 \\
\hline 80 & 8 & 13 & 12 & 15 & - & 39 & - \\
\hline 81 & 3 & 3 & 3 & 12 & 100 & 15 & - \\
\hline 82 & - & - & - & - & 14 & - & - \\
\hline 83 & - & - & - & - & 36 & 21 & - \\
\hline 84 & - & - & - & - & 71 & - & - \\
\hline 91 & 46 & 47 & 31 & 26 & - & 16 & 27 \\
\hline 92 & 42 & 13 & 12 & 31 & - & 19 & - \\
\hline 93 & 100 & 100 & 100 & 87 & 74 & 92 & - \\
\hline 94 & 9 & 12 & 14 & 42 & - & 15 & - \\
\hline 95 & - & - & - & 10 & 29 & - & - \\
\hline 96 & - & - & - & - & 42 & 11 & - \\
\hline 103 & - & - & - & - & - & - & 13 \\
\hline 105 & 12 & 3 & 4 & 8 & - & 8 & 23 \\
\hline 106 & 3 & - & - & - & - & - & - \\
\hline 107 & 5 & 4 & 7 & 30 & - & 10 & - \\
\hline 108 & - & - & - & 7 & 83 & - & - \\
\hline 109 & - & - & - & - & - & 10 & - \\
\hline 111 & - & - & - & - & 65 & - & - \\
\hline 115 & - & - & - & - & - & - & 24 \\
\hline 116 & - & - & - & - & - & - & 11 \\
\hline 117 & - & - & - & - & - & - & 38 \\
\hline 118 & - & - & - & - & - & - & 5 \\
\hline 121 & 12 & 8 & 13 & 30 & - & 31 & 36 \\
\hline 125 & - & - & - & - & 19 & - & - \\
\hline 133 & - & - & - & - & - & - & 20 \\
\hline 136 & 10 & 20 & 11 & 31 & - & 11 & - \\
\hline 139 & - & - & - & - & 63 & - & - \\
\hline 147 & - & - & - & - & - & - & 62 \\
\hline 148 & - & - & - & - & - & - & 100 \\
\hline 154 & - & - & - & - & 67 & - & - \\
\hline
\end{tabular}


obtains by the semi-empirical MNDO method is very important in order to understand the chemical processes that shared in biological systems.

\subsection{Structures Investigation of the Studied Compounds by Mass Spectra}

The fragmentation pathways of the main fragment ions formed from molecular ions of the studied compounds at $70 \mathrm{eV}$ are interpreted through fragmentation Schemes 1-7.

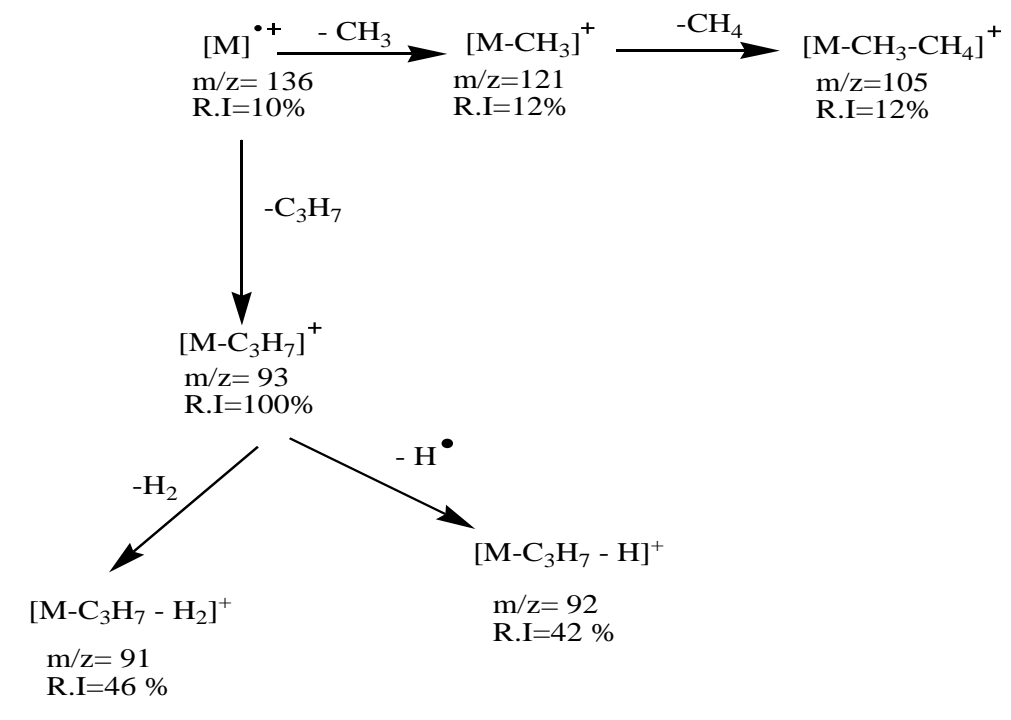

Scheme 1. Fragmentation pathway of $\alpha$-pinene.

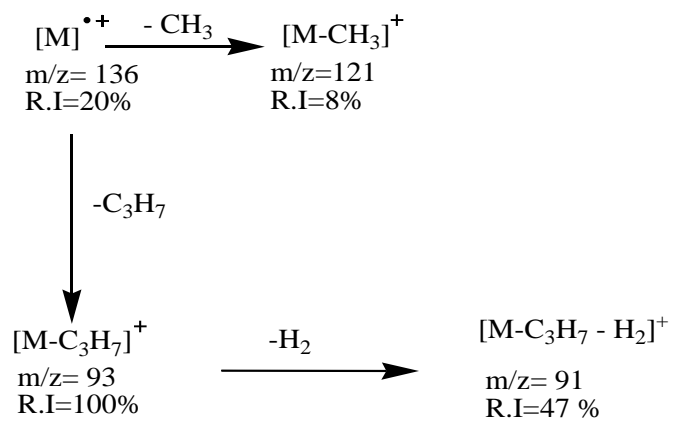

Scheme 2. Fragmentation pathway of sabinene.

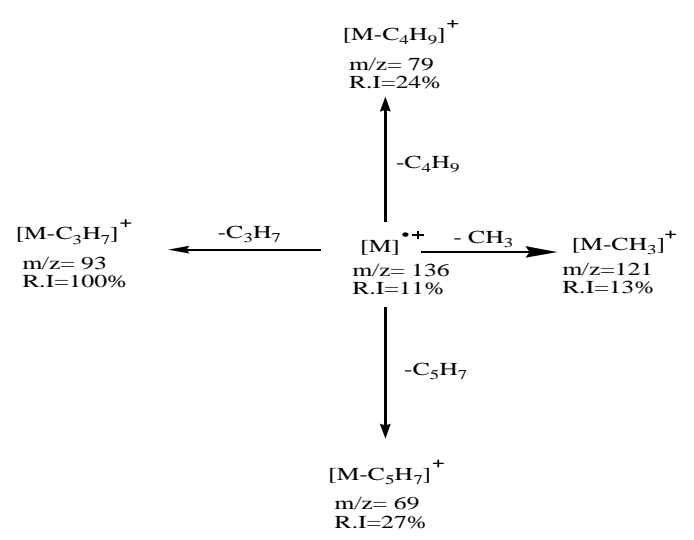

Scheme 3. Fragmentation pathway of $\beta$-pinene. 


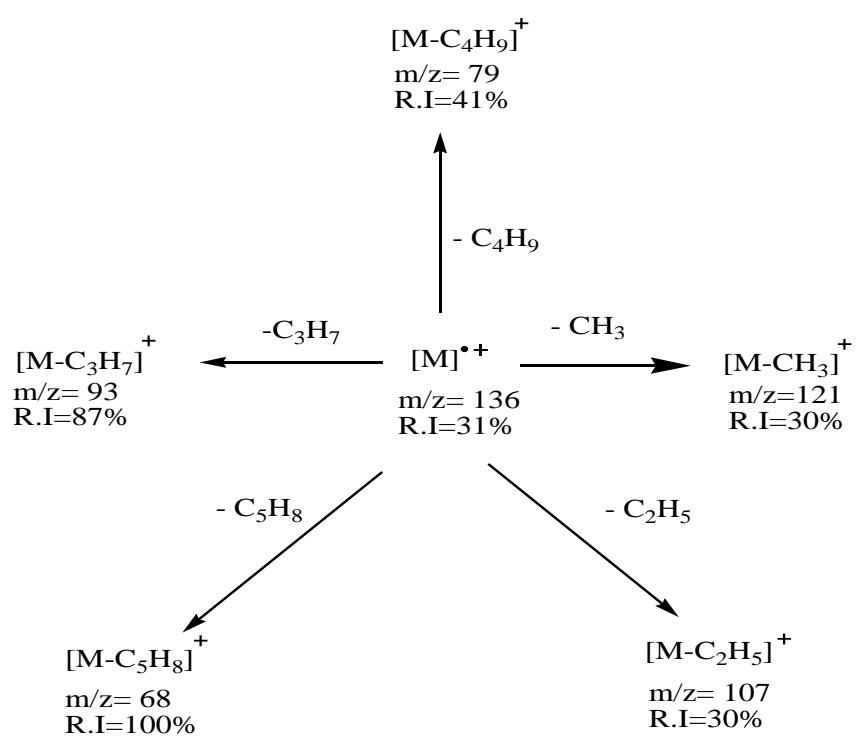

Scheme 4. Fragmentation pathway of d-limonene.

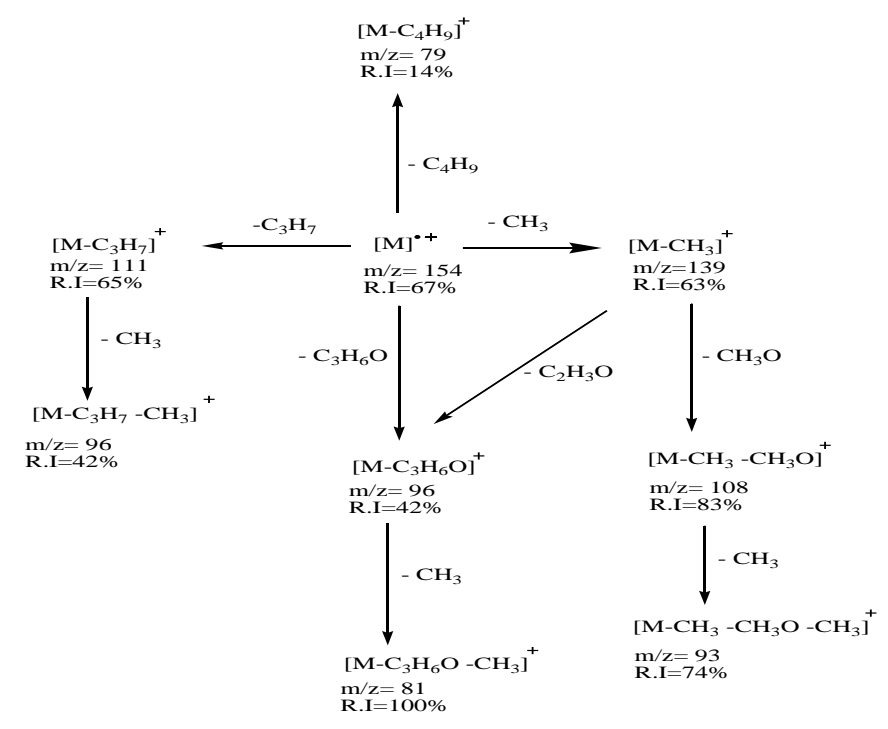

Scheme 5. Fragmentation pathway of eucalyptol.

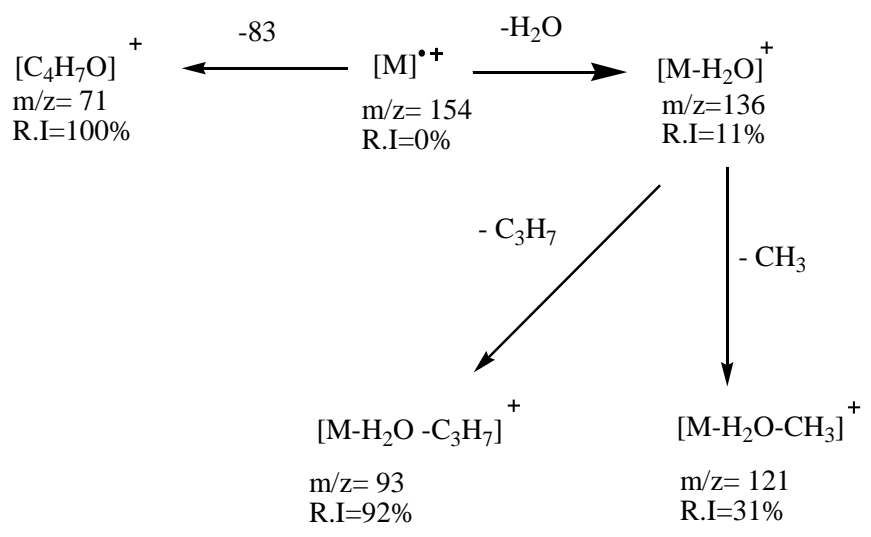

Scheme 6. Fragmentation pathway of l-linalool. 


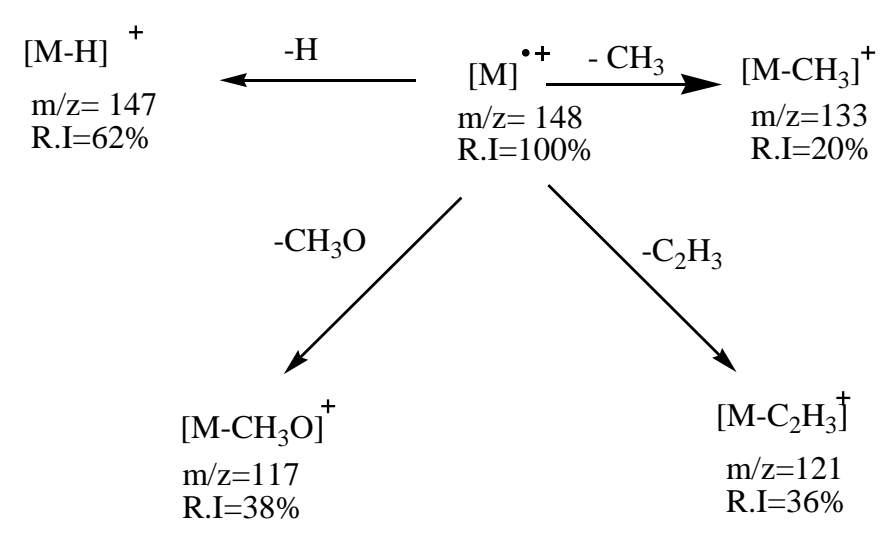

Scheme 7. Fragmentation pathway of estragole.

In our study we are divide the studied compounds to two groups, the first group contain $\alpha$-pinene, sabinene, $\beta$-pinene and d-limonene (isomers compounds) which have the chemical formula $\left(\mathrm{C}_{10} \mathrm{H}_{16}\right)$. These four compounds represent the isomers compounds which can be readily distinguished from its mass spectra through unimolecular fragmentation processes. The second group contains l-linalool, eucalyptol $\left(\mathrm{C}_{10} \mathrm{H}_{18} \mathrm{O}\right)$ and estragole $\left(\mathrm{C}_{10} \mathrm{H}_{12} \mathrm{O}\right)$ compounds which have an oxygen atom in their structures.

The mass spectra of these compounds show, the relative intensity (R I) of the molecular ions $[\mathrm{M}]^{+\bullet}$ at $\mathrm{m} / \mathrm{z}=$ 136 for the first group are low $(\alpha$-pinene R I $=10 \%$, sabinene R I $=20 \%, \beta$-pinene $\mathrm{R} \mathrm{I}=11 \%$ and d-limonene $\mathrm{R}$ $\mathrm{I}=31 \%)$. These aliphatic compounds have the cyclic structures which hardly produce higher abundance molecular ions in comparison with relative intensities of the second group (eucalyptol $\mathrm{m} / \mathrm{z}=154 \mathrm{R} \mathrm{I}=67 \%$, estragole $\mathrm{m} / \mathrm{z}=148 \mathrm{R} \mathrm{I}=100 \%$ ) except linalool $\mathrm{m} / \mathrm{z}=154$ which has linear structure compound which has no peak for the molecular ion. This is due to its low stability in the ion source.

The fragmentation processes of the first group are achieved by mean of their unimolecular dissociation of the parent ions by loss of $\mathrm{C}_{3} \mathrm{H}_{7}$ radical to produce the main fragment ion (base peak) $\left[\mathrm{M}-\mathrm{C}_{3} \mathrm{H}_{7}\right]^{+}$at $\mathrm{m} / \mathrm{z}=93$, which they are in stable cyclic structures (six or seven membered ring). The second fragmentation process of the molecular ion of is the formation of the fragment ion at $\mathrm{m} / \mathrm{z} 121$ which represents the ion $\left[\mathrm{M}-\mathrm{CH}_{3}\right]^{+}$with low relative intensities ( $\alpha$-pinene R I $=12 \%$, sabinene R I $=8 \%, \beta$-pinene R I $=13 \%$ and $\mathrm{D}$-limonene R I $=30 \%$ ). The base peak of the d-limonene in the first group is formed directly from the molecular ion by simple cleavages of C-C bond directly to form the fragment $\mathrm{C}_{5} \mathrm{H}_{8}{ }^{+}$ion at $\mathrm{m} / \mathrm{z}=68$ as shown in Schemes 1-4.

The fragmentation processes of the second group are achieved by mean of the loss of $\mathrm{CH}_{3}^{*}$ from the molecular ion to form the fragment ion $\left[\mathrm{M}-\mathrm{CH}_{3}\right]^{+}$at $\mathrm{m} / \mathrm{z} 139(\mathrm{R} \mathrm{I}=63 \%)$ and at $\mathrm{m} / \mathrm{z} 133(\mathrm{R} \mathrm{I}=20 \%)$ in the case of eucalyptol and estragole, respectively. On the other hand, the fragmentation process of the molecular ion of l-linalool achieved by mean of the loss of $\mathrm{H}_{2} \mathrm{O}$ to form the fragment ion $\left[\mathrm{M}-\mathrm{H}_{2} \mathrm{O}\right]^{+}$at $\mathrm{m} / \mathrm{z}=136(\mathrm{R} \mathrm{I}=11 \%)$ as shown in Schemes 5-7. In the case of eucalyptol, the mass spectrum show the fragment ion at $\mathrm{m} / \mathrm{z}=81$ have represented the most intense peak (base peak) which is formed by secondary process $\left[\mathrm{M}-\mathrm{C}_{3} \mathrm{H}_{6} \mathrm{O}-\mathrm{CH}_{3}\right]^{+}$as shown in Scheme 5.

\subsection{Semi-Empirical Molecular Orbital Calculations of the Studied Compounds}

The structure of each compound from our studied compounds was optimized using MNDO (semi-empirical molecular orbital method) to calculate thermochemical and energies data. The semi-empirical methods can be optimized for different purposes. For instance, MNDO method (see theoretical calculations paragraph and the fourth paragraph at introduction section) were used to calculate heats of formation and structures energies data of the studied compounds in the gas phase as shown in Table 3.

From these calculations, we have determined the values of heats of formation, total energies of the neutral and charged molecules and their ionization energies. These thermochemical data are important in the description of the conformational properties of the studied compounds and are not published before as our knowledge.

One can observe that the calculated values for the total energies for the first group (isomers structures) at the ground state $(\alpha$-pinene $=-34,707$, sabinene $=-34,708, \beta$-pinene $=-34,704$ and $\mathrm{d}$-limonene $=-34,722$ $\mathrm{Kcal} / \mathrm{mol})$, the calculated values of dipole moments $(\alpha$-pinene $=0.113$, sabinene $=0.122, \beta$-pinene $=0.112$ and 
Table 3. Some energies of the studied structures calculated within the MNDO framework.

\begin{tabular}{cccccccc}
\hline Compound & $\begin{array}{c}\Delta \mathrm{H}_{\mathrm{f}}(\mathrm{M}) \\
\mathrm{Kcal} / \mathrm{mol}\end{array}$ & $\begin{array}{c}\Delta \mathrm{H}_{\mathrm{f}}(\mathrm{M})^{+} \\
\mathrm{Kcal} / \mathrm{mol}\end{array}$ & $\begin{array}{c}\text { Total energy } \\
(\mathrm{M}) \\
\mathrm{Kcal} / \mathrm{mol}\end{array}$ & $\begin{array}{c}\text { Total energy } \\
(\mathrm{M})^{+} \\
\mathrm{Kcal} / \mathrm{mol}\end{array}$ & $\begin{array}{c}\mathrm{I} . \mathrm{e} \\
\text { e.V }\end{array}$ & $\begin{array}{c}\text { Binding energy } \\
(\mathrm{M}) \\
\mathrm{Kcal} / \mathrm{mol}\end{array}$ & $\begin{array}{c}\text { Dipole } \\
\text { moment }(\mathrm{M}) \\
\mathrm{D}\end{array}$ \\
\hline $\begin{array}{c}\alpha \text {-pinene } \\
\text { Sabinene }\end{array}$ & 17 & 217 & $-34,707$ & $-34,508$ & 8.7 & -2525 & 0.113 \\
$\beta$-pinene & 16 & 204 & $-34,708$ & $-34,521$ & 8.2 & -2527 & 0.1453 \\
d-limonene & 20 & 225 & $-34,704$ & $-34,499$ & 9 & -2522 & 0.1122 \\
Ecuolyptol & -52 & 209 & $-34,722$ & $-34,515$ & 9 & -2541 & 0.1229 \\
l-linalool & -34 & 166 & $-42,819$ & $-42,601$ & 9.4 & -2758 & 1.385 \\
Estragole & -8 & 168 & $-42,801$ & $-42,599$ & 8.7 & -2740 & 1.576 \\
\hline
\end{tabular}

$\mathrm{D}$-limonene $=0.145 \mathrm{D})$ and binding energies values $(\alpha$-pinene $=-2525$, sabinene $=-2527, \beta$-pinene $=-2522$ and D-limonene $=-2541)$ have similar values, respectively.

Also, for the second group (an oxygen atom in their structures) the calculated values of total energies (eucalyptol $=-42,819$, linalool $=-42,801$ and estragole $=-40,816 \mathrm{Kcal} / \mathrm{mol})$, dipole moments $($ ecuolyptol $=1.385$, linalool $=1.576$ and estragole $=1.18 \mathrm{D}$ ) and binding energies values (eucalyptol $=-2758$, linalool $=-2740$ and estragole $=-2402$ ) have also similar values (Table 3).

One can calculate the ionization energies of these compounds as listed in Table 3. The lowest value is $8.0 \mathrm{eV}$ for estragole compound, which is due to the phenyl group and oxygen atom in its structure. The presence of $\Pi$ bonds and lone pair electron reduce the EI value. One of the important values of the chemical properties of organic compounds are the heats of formation $\Delta \mathrm{H}_{\mathrm{f}}(\mathrm{M})$. The theoretical values of $\Delta \mathrm{H}_{\mathrm{f}}(\mathrm{M})$ are calculated by semiempirical MNDO method are 17, 16, 20 and $2 \mathrm{kcal} /$ mole for the first group and $-52,-34,-8$ for the second group. From these values the first group is relatively less stable than the second group which has an oxygen atom in their structures.

To our knowledge, no experimental or theoretical values for $\Delta \mathrm{H}_{\mathrm{f}}(\mathrm{M})$ and $\Delta \mathrm{H}_{\mathrm{f}}(\mathrm{M})^{+\bullet}$ and the energies values for the studied compounds were reported in the literature.

\section{Conclusion}

The experimental investigations show that the application of GC-MS can provide a rather detailed analysis of basil leaves by using a good obtained chromatogram and mass spectra. These experimental data together with the theoretical quantum chemical calculations (MNDO) give us more information about the chemical behavior of the studied molecules which may be important for many chemical and medical applications (all MNDO data and its contribution to understand the chemical behavior of the studied compounds are clear in Table 3 and Section 4.2.).

\section{References}

[1] Sajjadi, S.E. (2006) Analysis of the Essential Oils of Two Cultivated Basil (Ocimum basilicum L.) from Iran. DARU, 14, 128-130. http://daru.tums.ac.ir/index.php/daru/article/viewFile/278/278

[2] Runyoro, D., Ngassapa, O., Vagionas, K., Aligiannis, N., Graikou, K. and Chinou, I. (2010) Chemical Composition and Antimicrobial Activity of the Essential Oils of Four Ocimum Species Growing in Tanzania. Food Chemistry, 119, 311-316. http://dx.doi.org/10.1016/j.foodchem.2009.06.028

[3] Telci, I., Bayram, E., Yilmaz, G. and Avci, B. (2006) Variability in Essential Oil Composition of Turkish Basils (Ocimum basilicum L.). Biochemical Systematics and Ecology, 34, 489-497. http://dx.doi.org/10.1016/j.bse.2006.01.009

[4] Anačkov, G., Božin, B., Zorić, L., Vukov, D., Mimica-Dukić, N., Merkulov, L., Ružica Igić, Jovanović, M. and Boža, P. (2009) Chemical Composition of Essential Oil and Leaf Anatomy of Salvia bertolonii Vis. and Salvia pratensis L. (Sect. Plethiosphace, Lamiaceae). Molecules, 14, 1-9. http://dx.doi.org/10.3390/molecules14010001

[5] Wogiatzi, E., Papachatzis, A., Kalorizou, H., Chouliara, A. and Chouliaras, N. (2011) Evaluation of Essential Oil Yield and Chemical Components of Selective Basil Cultivars. Journal of Biotechnology \& Biotechnological Equipments, 25, 
2525-2527. http://dx.doi.org/10.5504/BBEQ.2011.0067

[6] Pripdeevech, P., Chumpolsri, W., Suttiarporn, P. and Wongpornchai, S. (2010) The Chemical Composition and Antioxidant Activities of Basil from Thailand Using Retention Indices and Comprehensive Two-dimensional Gas Chromatography. Journal of Serbian Chemical Society, 75, 1503-1513. http://dx.doi.org/10.2298/JSC100203125P

[7] Ismail, M. (2006) Central Properties and Chemical Composition of Ocimum basilicum. Essential Oil. Pharmaceutical Biology, 44, 619. http://dx.doi.org/10.1080/13880200600897544

[8] Lee, S., Umano, K., Shibamoto, T. and Lee, S. (2005) Identification of Volatile Components in Basil (L.) and Thyme Leaves (L.) and Their Antioxidant Properties. Food Chemistry, 91, 131-137. http://dx.doi.org/10.1016/j.foodchem.2004.05.056

[9] Klimánková, S., Holadová, K., Hajšlová, J., Cajka, T., Poustka, J. and Koudela, M. (2007) Roma Profile of Five Basil (Ocimum basilicum L.) Cultivars Grown under Conventional and Organic Conditions. Food Chemistry, 107, 464-472. http://dx.doi.org/10.1016/j.foodchem.2007.07.062

[10] Cody, M., Laramee, J.A., Michael Nilles, J. and Dupont Durst, H. (2005) Direct Analysis in Real Time Mass Spectrometry. JEOL News, 40, No. 1. https://www.chem.utoronto.ca/_shared/files/facilities/mass/DART_Mass_Spectrometry.pdf

[11] Watson, J.J.T. and Sparkman, O.D. (2007) Introduction to Mass Spectrometry: Instrumentation, Applications, and Strategies for Data Interpretation. 4th Edition, John Wiley \& Sons, Ltd., USA. http://eu.wiley.com/WileyCDA/WileyTitle/productCd-0470516348.html

[12] White, K.A.F. and Wood, M.G. (1986) Mass Spectrometry: Application in Science and Engineering. Wiley \& Sons, Inc., USA. http://www.amazon.com/Mass-Spectrometry-Applications-Science-Engineering/dp/0471092363

[13] Curtiss, L.A. and Raghavachari, K. (1969) "Computational Thermochemistry: Prediction and Estimation of Thermodynamics. American Chemical Society, Washington DC. http://trove.nla.gov.au/work/7468809?selectedversion=NBD13645686

[14] Dewar, M.J.S. (1969) The Molecular Orbital Theory of Organic Chemistry. McGraw-Hill, New York.

[15] Pople, J.A. and Beveridge, D.L. (1970) Approximate Molecular Orbital Theory. McGraw-Hill, New York. http://www.amazon.com/Approximate-Molecular-Orbital-Theory-Beveridge/dp/B004CFL4KY

[16] Murrell, J.N. and Harget, A.J. (1972) Semiempirical Self-Consistent-Field Molecular Orbital Theory of Molecules. Wiley, New York.

http://www.amazon.com/Semi-empirical-Self-consistent-field-molecular-orbital-Theory-Molecules-Murrell/dp/047162 $\underline{6805}$

[17] Segal, G.A., Ed. (1977) Modern Theoretical Chemistry. Springer, New York. http://link.springer.com/bookseries/10920

[18] Dewar, M.J.S. (1975) Quantum Organic Chemistry. Science, 187, 1037-1044. http://dx.doi.org/10.1126/science.187.4181.1037

[19] Jug, K. (1980) Quantum Chemical Methods and Their Applications to Chemical Reactions. Theoretica Chimica Acta, 54, 263-300. http://dx.doi.org/10.1007/BF00552463

[20] Dewar, M.J.S. (1985) Applications of Quantum Mechanical Molecular Models to Chemical Problems. Part 70. Quantum Mechanical Molecular Models. The Journal of Physical Chemistry, 89, 2145-2150. http://dx.doi.org/10.1021/j100257a004

[21] Thiel, W. (1988) Semiempirical Methods: Current Status and Perspectives. Tetrahedron, 44, 7393-7408. http://dx.doi.org/10.1016/S0040-4020(01)86235-9

[22] Stewart, J.J.P. (1990) MOPAC: A Semiempirical Molecular Orbital Program. Journal of Computer-Aided Molecular Design, 4, 1-103. http://dx.doi.org/10.1007/BF00128336

[23] Stewart, J.J.P. (1991) Semiempirical Molecular Orbital Methods. In: Lipkowitz, K.B. and Boyd, D.B., Eds., Reviews in Computational Chemistry, Vol. 2, VCH Publishers, New York, 45-81.

http://onlinelibrary.wiley.com/book/10.1002/9780470125793 http://dx.doi.org/10.1002/9780470125793

[24] Zamer, M.C. (1990) Semiempirical Molecular Orbital Methods. In: Lipkowitz, K.B. and Boyd, D.B., Eds., Reviews in Computational Chemistry, Vol. 1, VCH Publishers; New York, 313.

http://onlinelibrary.wiley.com/book/10.1002/9780470125786 http://dx.doi.org/10.1002/9780470125786

[25] Thiel, W. (1996) Perspectives on Semiempirical Molecular Orbital Theory. Advances in Chemical Physics, 93, 703757. http://dx.doi.org/10.1002/9780470141526.ch10

[26] Ribeiro da Silva, M.A.V. and Matos, M.A.R. (1997) Recent Work on the Thermochemistry of Some Nitrogen Hetero- 
cycles. Pure \& Applied Chemistry, 69, 2295-2306. http://dx.doi.org/10.1351/pac199769112295

[27] Elsherbiny, E.A., El-Khateeb, A.Y. and Azzaz, N.A. (2016) Chemical Composition and Fungicidal Effects of Ocimum basilicum Essential Oil on Bipolaris and Cochliobolus Species. Journal of Agricultural Science and Technology (Under Press).

[28] Dewar, M.J.S. and Thiel, W. (1977) Ground States of Molecules, 38. The MNDO Method. Approximations and Parameters. Journal of American Chemical Society, 99, 4899-4907. http://dx.doi.org/10.1021/ja00457a004

[29] Thiel, W. (2003) Handbook of Molecular Physics and Quantum Chemistry. Wilson, S. Ed., Vol.2, Wiley, 487-502.

[30] HyperChem ${ }^{\mathrm{TM}}$ (2002) Release 7.5 Pro for Windows “Molecular Modeling System”. Hypercube Inc. 